\title{
NovES INSCRIPCIONS ROMANES D’AlZIRA (VALÈNCIA)
}

Donem a conèixer dues noves inscripcions romanes trobades a la població d'Alzira (la Ribera Baixa) per un de nosaltres (Agustí Ribera), la primera dissortadament desapareguda i la segona recentment localitzada ${ }^{1}$.

\section{INSCRIPCIÓ NÚM. 1}

La primera inscripció es va trobar en les obres de construcció de la caserna de la Guàrdia Civil de la localitat cap a l'any 1950. Aquesta es va alçar sobre el fossar i un lateral de l'antiga església de Santa Maria, i en part sobre l'antic traçat del carrer Major del mateix nom. L'església estava situada a l'entrada de la població, al costat de la muralla i prop del pont de Sant Gregori, i es va construir després de la conquesta en 1242 al lloc on es trobava una de les seues mesquites. Destruïda en part l'any 1936, va ser totalment derrocada amb posterioritat. La caserna es va edificar segons el projecte de l'arquitecte municipal Juan F. Guardiola. De les troballes efectuades en aquestes obres tenim notícia per uns apunts presos pel pintor Ricardo Fluixá Gómez (1918-1994), natural d'Alzira (Montagud 1996). Es tracta d'un full on figura un croquis a escala 1:100 amb les rases excavades per a la construcció de l'esmentada caserna (fig. 1), corresponents al mur perimetral exterior de l'edifici, de planta aproximadament quadrada, i al pati de llums obert a l'interior. En el croquis es representen les diferents restes antigues que aquell hi va poder identificar: nombrosos murs de fábrica antigua, dos pous, un fragmento de lápi$d a$ i en el sector N-NO restos humanos. Almenys una part dels murs trobats devien pertànyer a estructures relacionades amb l'esmentada església.

El fragment d'inscripció apareix representat únicament en un dibuix (fig. 2), sense determinar el lloc exacte de la troballa, les dimensions ni el tipus de pedra. Tal vegada formava part d'algun dels murs trobats, on es podia haver emprat com a material constructiu. Sembla tractar-se d'una porció un poc menor de la meitat dreta d'una llosa amb el camp epigràfic rebaixat o delimitat per una motlura. Els tres costats originals es trobaven ben conservats i la línia de fractura es disposava diagonalment de dreta a esquerra.

$$
\begin{aligned}
& \text {---]O } \\
& ---] \mathrm{OR} \\
& ---] \mathrm{BI} \\
& ---\mathrm{O}] \mathrm{BIIT} \\
& \text {---AN(NIS)] XXXII }
\end{aligned}
$$


El text consta de cinc línies, de les quals només es conserva la part final, amb una extensió compresa entre una i cinc lletres. Aquestes apareixen representades amb claredat, per la qual cosa pot deduir-se que es trobaven prou ben conservades i la transcripció sembla segura. Es tracta d'un text de caràcter funerari. No estan senyalats els punts. L'ordinatio sembla acurada i segueix un eix de simetria. En la primera línia la terminació -O pot correspondre a la desinència en datiu del nomen del/la difunt/a, ja que l'espai restant al final no exigeix el trencament de la paraula; si aquesta interpretació és correcta, cal excloure la presència de la dedicatòria als déus Mans. En la segona, les lletres OR poden pertànyer al cognomen. La terminació -BI de la tercera podria correspondre a alguna variant de la fórmula en què apareix el pronom sibi. En la quarta es veuen quatre lletres que deuen correspondre a la forma verbal obiit. La cinquena i darrera línia conté un numeral que deu correspondre a l'edat del/la difunt/a, que sembla ser XXXII, encara que el primer i el segon signe es troben més separats que la resta. En les fórmules en què figuren el verb i el numeral, davant d'aquest apareix almenys el terme annis, que hi podia anar abreviat.

L'ús de la forma verbal obiit no és freqüent en les inscripcions romanes del País Valencià, ja que la trobem en una sola ocasió en una estela desapareguda del municipi Lucentum (el Tossal de Manises, Alacant) (IRPV VI 73, amb la forma obit).

Les possibilitats de datació d'aquesta inscripció són prou limitades pel fet de no conservar-se i de trobar-se incompleta. Senyalem els trets més significatius: es tracta d'una llosa, el camp epigràfic sembla estar rebaixat, el text sembla anar en datiu i pot haver-se utilitzat una fórmula que inclou el pronom sibi. Amb les reserves naturals, sembla raonable una datació en el segle II.

\section{INSCRIPCIÓ NÚM. 2}

La segona inscripció es va identificar entre un grup de carreus conservats al solar de l'antiga Casa del Rei, un edifici situat al costat del carrer Major de Santa Maria, al costat de la muralla de la població, on s'havia emprat com a brancal d'una porta. Possiblement es tractava d'una gran construcció de tàpia que va servir com a Casa dels Jurats després de la conquesta el 1242, on segons la tradició residia el rei Jaume I quan sojornava a la vila. Per tant, la procedència de l'apígraf és desconeguda. Es trac-

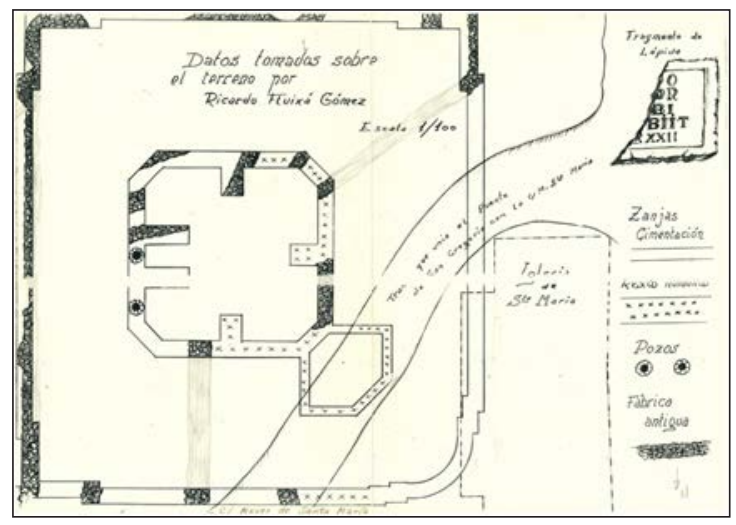

Fig. 1. Croquis de R. Fluixá amb indicació de les restes identificades en les rases de construcció de la caserna.

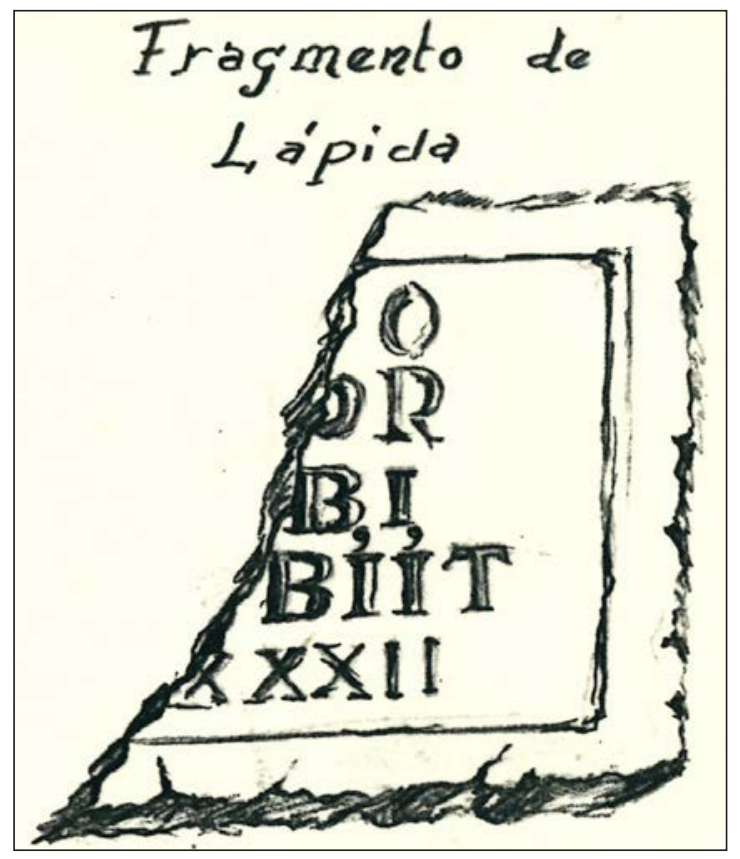

Fig. 2. Detall del dibuix de la làpida al croquis de R. Fluixá.

ta d'un carreu paral-lelepípede de pedra calcària clara amb unes dimensions de $60 \times 83,5 \times 33 \mathrm{~cm}$ (figs. 3-4). Presenta un important rebaixament en una franja perimetral de la cara frontal -a manera d'un groller encoixinatd'11,5 cm de profunditat i fins a $11 \mathrm{~cm}$ d'amplària. Aquest afecta la major part del camp epigràfic, que d'aquesta manera només es conserva en una reduïda porció de la zona central de 19 x $50 \mathrm{~cm}$. Del text es veu part 


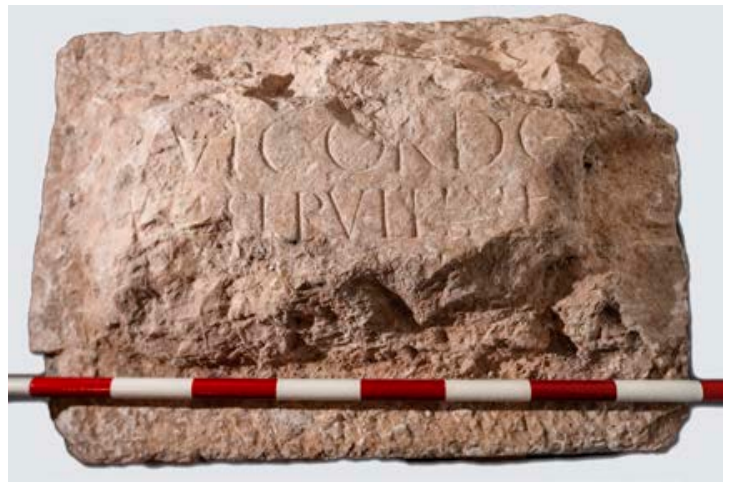

Fig. 3. Inscripción provinent de calcària del solar de l'Antiga Casa del Rei.

de tres línies, de les quals les dues primeres conserven tota la seua alçària i la tercera només l'extrem superior d'algunes lletres. Amb seguretat devia haver-hi, almenys, una línia per damunt de la primera conservada i una altra per davall de la darrera, de manera que el text constava d'un mínim de 5 línies. L'altura de les lletres és de 7,5 cm en la primera línia i de 5,5 cm en la segona. En la primera es veu un punt triangular amb vèrtex cap avall. La lletra és molt acurada i presenta reforços; com a trets particulars podem dir que la $\mathrm{O}$ és rodona i la $\mathrm{P}$ és oberta. El text, restituït parcialment, és com segueix:

$$
\begin{aligned}
& \text {---h]uic } \cdot \text { ordo [saetab(itanorum)] } \\
& \text { [--- locu]m sepult(urae) inp[ensam } \\
& \text { funeris --- decrevit ---] }
\end{aligned}
$$

A pesar del seu estat fragmentari, aquesta inscripció resulta del major interès perquè conté la dedicatòria del senat municipal de Saetabis al que sens dubte fou un destacat personatge de la ciutat, el nom del qual malauradament no s'ha conservat. Els pocs mots que s'hi poden reconèixer resulten inequívocs, sobretot en el cas de l'ordo de la primera línia, al qual s'anteposa el demostratiu [h] uic que pot restituir-se amb seguretat. A continuació podia seguir el gentilici, que normalment va abreviat $\mathrm{i}$ pot expressar-se també amb les formes saetab(itanus) o Saetabi Aug(ustanorum), o fins i tot directament la forma verbal decrevit. En la segona línia es llegeix abreviat el terme sepult(urae) precedit d'un altre del qual només resta un traç vertical que deu correspondre a la darrera lletra de locum; ací no es distingeix cap punt i poden llegir-se les lletres IN seguides d'un traç vertical que deu correspondre a l'acusatiu inp[ensam], escrit amb $\mathrm{N}$ en lloc de

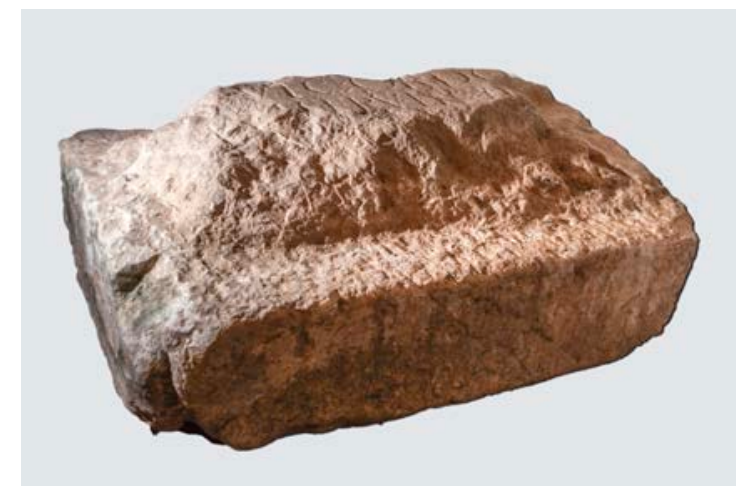

Fig. 4. Vista lateral de la inscripció on s'aprecia el rebaixament lateral.

M, un error d'escriptura que s'ha documentat en altres ocasions $^{2}$. De la tercera línia només resulten visibles dos reforços que possiblement pertanyen a l'extrem superior de dues lletres contigües, que poden correspondre a alguns dels termes que completen aquest tipus de fórmules que presenten nombroses variants; és possible que, a més de la referència al lloc de la sepultura, també hi figuraren el mot statuam, si es tractava d'un pedestal, i la referència a l'elogi fúnebre o laudatio que freqüentment apareixen en aquest tipus de dedicatòries. En la part anterior a la conservada del text -almenys una línia- figuraria el nom i potser el cursus honorum abreviat del personatge homenatjat, i en la part posterior -d'extensió semblantes completaria la fórmula de la dedicatòria de l'ordo.

Així, doncs, possiblement es tractava d'un pedestal que, amb la seua corresponent estàtua, fou erigit per decisió de l'ordo setabense en honor del difunt. En la reduïda part conservada del text figura aquell i les mencions del lloc de la sepultura i probablement de les despeses del funeral. És prou freqüent que els senats municipals decreten, junt amb la laudatio i els impensa funeris, la concessió del lloc de sepultura i l'erecció d'una estàtua, distincions adequades per retre honor als membres més destacats de les elits locals i efectius instruments d'autorepresentació. Pel que fa a la cronologia, malgrat que la part conservada del text és molt reduïda, la bona factura de les lletres permet aproximar una datació entre la segona meitat del s. I i la primera del II.

Aquesta és la segona inscripció trobada a Alzira amb una dedicatòria pública del municipi setabense a un destacat personatge, possiblement un antic magistrat. L'altra fou trobada a la vil-la del Sequer de Sant Bernat del mateix terme municipal d'Alzira (López Peris et al. 2013), 
que està situada a $29 \mathrm{~km}$ de Xàtiva per carretera. En aquesta (CIL II 3655 = IRPV III 96) la fórmula emprada per honorar-lo és per decret dels decurions: $M($ arco) Clodio / M(arci)f(ilio) Gal(eria) Celerif(actus) / exd(ecreto) d(ecurionum) / Saetabi Augu / stanorum, mentre que en la que ací presentem és l'ordo esmentat expressament qui realitza la dedicatòria de forma pòstuma. El segon aspecte que destaca d'ambdues dedicatòries és que els monuments, possiblement sengles pedestals amb les seues corresponents estàtues, es van erigir en els fundi dels homenatjats, una pràctica freqüent documentada en altres casos a Hispània (Melchor 2013). En aquest cas, la menció a la sepultura prova el seu caràcter funerari. Ambdues constitueixen un bon exemple de com el poder econòmic de les oligarquies municipals descansava freqüentment en la propietat i explotació de la terra. El fet que crida l'atenció és la coincidència de la troballa de dues dedicatòries en una mateixa localitat. D'altra banda, l'aparició del senat local com dedicant d'inscripcions -normalment pedestals- és un fet freqüent, sobretot en àmbits urbans, on solen concentrar-se als fòrums, però no ho és tant en el món rural. Aquestes dedicatòries proporcionen una informació bàsica per al coneixement de la praxi administrativa de les ciutats, com s'ha pogut comprovar en el Conventus Tarraconensis (García Riaza 2005: 476-481). En el cas del municipi setabense, a més de la ja esmentada d'Alzira, es coneixen altres dos casos en sengles dedicatòries ex d(ecreto) d(ecurionum) Saetabi Augustanorum trobades a la mateixa ciutat: la primera a un emperador desconegut (CIL II $3625=I R P V$ III 4) i la segona en un pedestal eqüestre erigit en honor d'un altre destacat personatge local: M. Granius M. f. Gal. Super[----] (CIL II 3624 = IRPV III 6).

Aquest tipus de dedicatòries s'ha documentat en 27 ocasions a les províncies hispàniques, majoritàriament a la Bètica (Melchor 2007). Al País Valencià, a banda dels casos d'Alzira ací esmentats, només es coneixen altres dues inscripcions de Valentia en què l'ordo colonial decreta la publica laudatio, el locus sepulturae, la funeris impensa i l'statua (IRPV V, 28a, 43) i una tercera en què figuren els mateixos honors amb l'excepció de la laudatio $(I R P V \mathrm{~V}, 42)$.

D'altra banda, a més de M. Clodius M.f. Gal. Celer, del territorium de Saetabis coneixem un altre possessor del qual s'ha pogut excavar parcialment la villla, situada a la propera població de L'Ènova: P. Cornelius Iunianus (Albiach, De Madaria 2005). Aquest apareix també com a dedicant del personatge anteriorment esmentat.
A Alzira es coneixien fins ara tres epígrafs, en tots els casos troballes antigues (CIL II 3655, 3656, $3657=I R P V$ III 96, 97, 98), dos de caràcter funerari i el pedestal anteriorment esmentat. Amb les dues noves troballes que ací presentem, són ja cinc els epígrafs coneguts en aquesta zona de la Ribera del Xúquer pròxima al que sens dubte fou el fines septentrional del territori del municipi setabense, el riu Sucro.

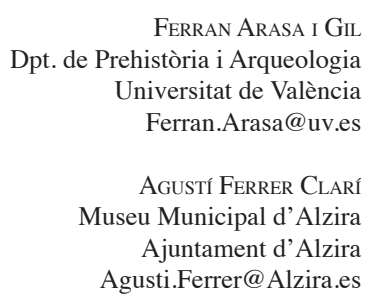

\section{NOTAS}

1. La visita al Museu Municipal d'Alzira i l'autòpsia de l'epígraf conservat la vam fer el dia 26 de abril de 2015. Volem agrair als professors J. M. Abascal i P. P. Ripollès la revisió del text. Les fotografies són de Pedro Benedito (Alzira).

2. Es poden veure els casos reunits per Dardaine $(1980,1992)$ en els seus treballs sobre la Bètica: Italica, Hispalis, Astigi, Munigua, Ilurco, Ilipa, Arva i Lacilbula. Sobre aquesta fórmula, a més dels treballs d'aquesta autora es poden veure els de Gallego (1994) sobre les referides a dones i les més recents de Melchor (2007, 2013).

\section{BIBLIOGRAFIA}

ALBIACH, R.; DE MADARIA, J. L. (coords.) (2005): La villa romana de Els Alters (L'Ènova, Valencia), Valencia.

DARDAINE, S. (1980): La formule épigraphique impensam remisit et l'évergétisme en Bétique, $M C V$ 16, 39-55.

DARDAINE, S. (1992): Honneurs funèbres et notables municipaux dans l'épigraphie de la Bétique, Habis 23, 139-151.

EDCS = Epigraphik-Datenbank Clauss/Slaby: http://www.manfredclauss.de/ (6/09/2015).

GALLEGO, M. DEL H. (1994): Laudationes, impensa funeris, locus sepulturae: la mujer y los honores funerarios en Hispania, Hispania Antiqua 18, 267-275.

GARCÍA RIAZA, E. (2005): La praxis administrativa en las ciudades del Conventus Tarraconensis (Hispania Citerior), MEFRA 117 (2), 465-489.

HISPANIA EPIGRAPHICA: http://eda-bea.es/ (6/09/2015).

IRPV III = CORELL, J. (2006): Inscripcions romanes del País Valencià. III. (Saetabis i el seu territori), València. 
IRPV V = CORELL I VICENT, J. (2009): Inscripcions romanes del País Valencià. V. Valentia i el seu territori, València.

IRPV VI = CORELL I VICENT, J. (2012): Inscripcions romanes del País Valencià. VI. (Ilici, Lucentum, Allon, Dianium i els seus territoris), València.

LÓPEZ PERIS, J. E.; SAÑUDO, P.; VERDASCO, C. (coords.) (2013): El yacimiento arqueológico del Sequer de Sant Bernat, Madrid.
MELCHOR, E. (2007): Sobre la presencia de la laudatio y la ausencia del funus publicum en la epigrafía de Hispania y de la Mauritania Tingitana, Epigraphica 69, 321-329.

MELCHOR, E. (2013): Entre la urbs y el fundus: conmemoración funeraria y honorífica de las élites locales hispano-romanas en sus propiedades rústicas, Veleia 30, 119-142.

MONTAGUD, B. (1996): Noticia bibliográfico artística del pintor alzireño Ricardo Fluixá Gómez, Al-Gezira 9, 9-27. 